\title{
Effect of metoclopramide on gastric function in man
}

\author{
A. M. CONNELL AND J. D. GEORGE \\ From the Department of Surgery, Institute of Clinical Science, \\ Royal Victoria Hospital, Belfast
}

SUMMARY The effects of metoclopramide on gastric emptying and gastric secretion have been assessed in man using the double sampling test meal. Metoclopramide increases the rate of emptying of the stomach. The magnitude of the effect is directly related to the initial emptying time. Metoclopramide has no effect on the acid response to a water test meal.

In 1964 Justin-Besancon and Laville described the pharmacological action of metoclopramide (2 methoxy, 5-chloroprocainamide). In animals it inhibits vomiting induced centrally by apomorphine and accelerates emptying of the stomach (JustinBesancon, Laville, and Thominet, 1964; Jacoby and Brodie, 1967), although it does not appear to have a direct action on smooth muscle. In man, the use of metoclopramide promotes gastric emptying as assessed by barium meal and accelerates the rate of transit through the small intestine (Margieson, Sorby, and Williams, 1966; James and Hume, 1968). In addition a double blind clinical trial has shown metoclopramide to be better than a placebo in preventing postoperative nausea and vomiting (Handley, 1967).

As yet, however, no quantitative assessment of its effect on gastric emptying in man has been presented. In this study we demonstrate the value of metoclopramide in increasing the rate of gastric emptying as assessed by the double-sampling test meal. The effect of metoclopramide on gastric secretion has also been assessed.

\section{METHODS}

The rate of emptying of the stomach and the acid secretory response were estimated using a water test meal. Using phenol red as a marker and a double sampling technique the rate of gastric emptying can be accurately estimated. The emptying time, defined as the time taken for the gastric contents to be reduced to $10 \mathrm{ml}$ after a test meal of $750 \mathrm{ml}$ (Hunt and Spurrell, 1951), was calculated in each case. Full details of the method have been described (George, 1968a). By estimating the concentration of $\mathrm{Cl}^{-}$and $\mathrm{H}^{+}$in the fluid sampled from the stomach, the acid secreted in response to the test meal can also be assessed (Hunt, 1951). Two indices

This work was undertaken during the tenure of a Royal Victoria Hospital Research Fellowship. of acid secretion were examined. The total amount of acid secreted in the first 30 minutes after the test meal was measured in each case, and also the concentration contact-time index. This is an expression of the concentration of acid in the gastric contents and the time during which it remains in the stomach, and reflects the time of exposure of the gastric mucosa to acid (George, 1968b).

\section{PATIENTS}

Gastric emptying was assessed in 19 patients who were being investigated on account of digestive symptoms. These comprised 10 patients with duodenal ulcer, six with gastric ulcer, and three with dyspepsia but no demonstrable radiological abnormality. In addition one normal subject was tested twice.

Each patient had gastric emptying and secretion estimated on two occasions on different days. The patient was given an injection before each test meal. On one occasion $10 \mathrm{mg}$ metoclopramide was given by slow intravenous injection and on the other intravenous saline was used. The order of the injections was randomized and the tests were performed and results analysed without knowledge of the nature of the injection given.

\section{RESULTS}

Table I presents the time of emptying in each subject after the injection of placebo and metoclopramide respectively. The emptying time decreased in 19 of the 21 studies although in 11 instances where emptying was in the normal range of between 50 and $90 \mathrm{~min}$ (George, 1968a) the change was slight.

In Fig. 1, the decrease in emptying time produced by metoclopramide has been plotted against the emptying time measured after injection of saline. The high correlation $(\mathrm{r}=+0.95, \mathrm{p}<0.001)$ indicates that the effect of metoclopramide is related to the initial rate of emptying, and has the greatest effect in patients with a delayed rate of gastric evacuation. 
TABLE I

RATE OF EMPTYING OF THE STOMACH IN 42 TESTS AFTER INTRAVENOUS INJECTION OF 10 MG METOCLOPRAMIDE OR A PLACEBO INJECTION

\begin{tabular}{rlrr} 
Patient & Diagnosis & \multicolumn{2}{c}{ Emptying Time } \\
\cline { 3 - 4 } & & Placebo & Metoclopramide \\
\hline 1 & & 48 & 50 \\
2 & Radiograph negative & 56 & 55 \\
3 & Duodenal ulcer & 65 & 63 \\
& Normal & 69 & 58 \\
4 & Duodenal ulcer & 66 & 60 \\
5 & Duodenal ulcer & 68 & 63 \\
6 & Duodenal ulcer & 70 & 60 \\
7 & Duodenal ulcer & 71 & 68 \\
8 & Duodenal ulcer & 73 & 47 \\
9 & Duodenal ulcer & 80 & 94 \\
10 & Duodenal ulcer & 80 & 49 \\
11 & Gastric ulcer & 102 & 61 \\
12 & Gastric ulcer & 103 & 82 \\
13 & Radiograph negative & 108 & 102 \\
14 & Gastric ulcer & 116 & 82 \\
15 & Gastric ulcer & 160 & 113 \\
16 & Radiograph negative & 168 & 79 \\
17 & Duodenal ulcer & 201 & 110 \\
18 & Duodenal ulcer & 215 & 98 \\
19 & Gastric ulcer & 253 & 174 \\
20 & Gastric ulcer & 270 & 98 \\
& & 116 & 79 \\
& & Mean & 116
\end{tabular}

${ }^{1}$ Patients 11 to 20 suffered nausea in the period in which the study was performed.

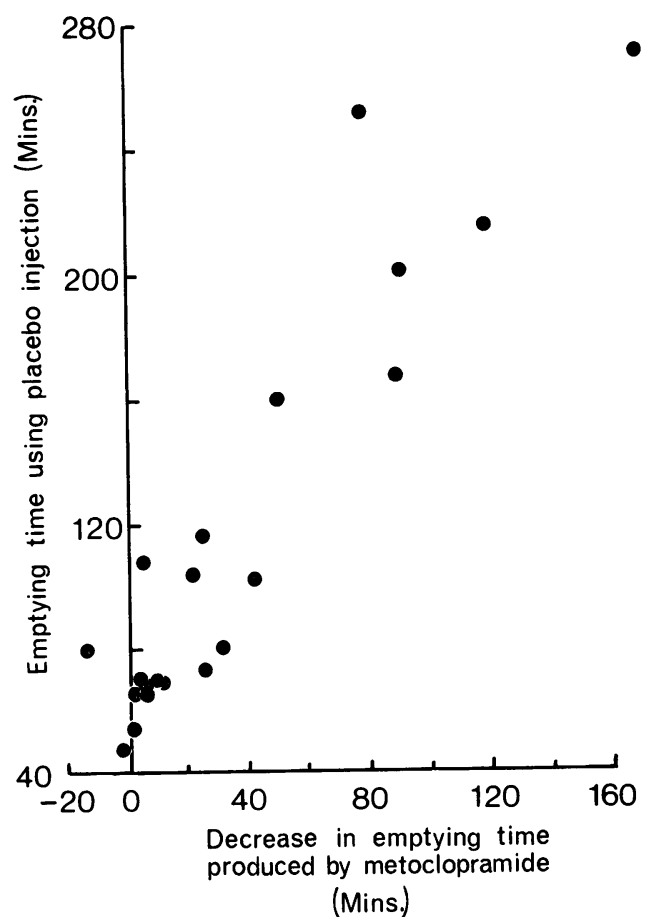

FIG. 1. The magnitude of the effect of metoclopramide related to the initial rate of emptying of the stomach.
Ten of the 21 studies were done on persons who were suffering from nausea in the period in which the study was done. All had delayed emptying and in all there was an increased rate after metoclopramide. The beneficial effect on emptying did not appear to be related to the nature of the gastric lesion.

Metoclopramide did not affect the amount of acid secreted in response to a test meal (Table II). The exposure of the gastric mucosa to acid, however, is reduced by metoclopramide, as indicated by the reduced concentration contact-time index (Fig. 2). This decrease can be explained by the increase in the rate of emptying.

TABLE II

ACID SECRETED IN 30 MIN AFTER A WATER TEST MEAL GIVEN EITHER AFTER INTRAVENOUS INJECTION OF METOCLOPRAMIDE 10 MG OR AN INERT INJECTION

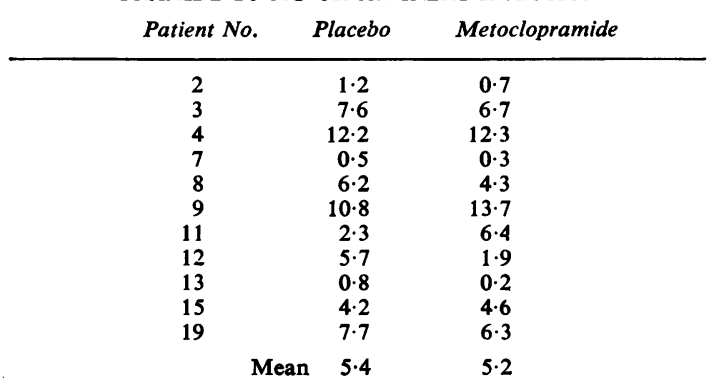

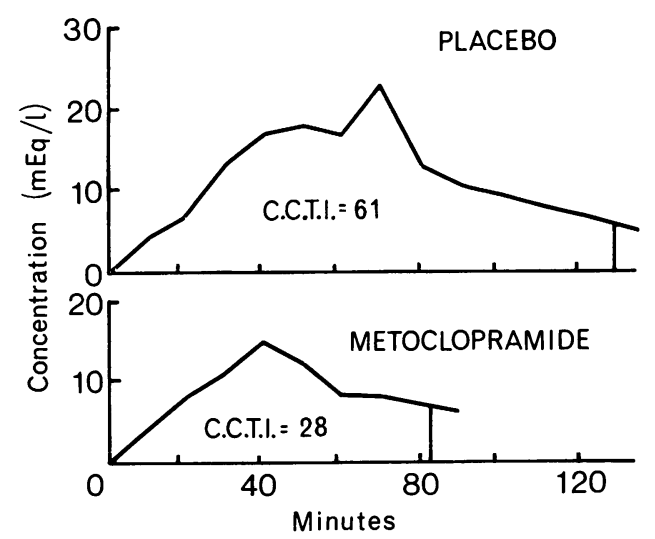

FIG. 2. The effect of metoclopramide on the concentration contact-time index (CTTI) of gastric secretion.

\section{DISCUSSION}

The effect of metoclopramide on two aspects of gastric function has been examined: its effect on the rate of emptying and its effect on gastric secretion. 
Metoclopramide produces a significant increase in the rate of evacuation of water from the stomach. This effect, however, is much more marked in patients who have a delayed rate of emptying. In the 10 subjects who had a normal rate of emptying the effect of the drug was very slight and in two subjects the calculated emptying time was slightly longer with metoclopramide than it was with the placebo. In the 10 subjects who had a delayed rate of emptying, metoclopramide produced a very significant increase in the rate of emptying. Its effect is related to the initial emptying time and does not appear to be related to the clinical diagnosis. It is not possible from these studies to say if the change was secondary to the relief of nausea or due to some more direct action in the gastrointestinal muscle. Metoclopramide did not have any direct effect on the secretion of acid by the parietal cells. It does, however, appear to have a significant indirect effect on the time during which the gastric mucosa is exposed to acid. The concentration contact-time index was found to be considerably reduced by metoclopramide, an effect which could be explained by the increased rate of gastric evacuation.

Chronic gastric ulcer has been attributed to gastric stasis (Dragstedt, 1956; Johnson, 1957; Burge, 1965) and in many patients with gastric ulcer the gastric mucosa is exposed to the action of acid for a longer period than normal (George, 1968b).
By reducing the contact time metoclopramide may help patients with chronic gastric ulcer.

We are grateful to Beechams Ltd for supplies of Metoclopramide.

\section{REFERENCES}

Burge, H. (1965). Pathogenesis of gastric ulceration. Lancet, 2, 39-40. Dragstedt, L. R. (1956). A concept of the etiology of gastric and duodenal ulcers. Gastroenterology, 30, 208-220.

George, J. D. (1968a). New clinical method for measuring the rate of gastric emptying: the double sampling test meal. Gut, 9 , 237-242.

- (1968b). Gastric acidity and motility. Amer. J. dig. Dis., 13, 376-383.

Handley, A. J. (1967). Metaclopramide in the prevention of postoperative nausea and vomiting. Brit. J. clin. Prac., 21, 460-462.

Hunt, J. N. (1951). The secretory pattern of the stomach of man. J. Physiol. (Lond.), 113, 169-184.

- and Spurrell, W. R. (1951). The pattern of emptying of the human stomach. J. Physiol. (Lond.), 113, 157-168.

Jacoby, H. I., and Brodie, D. A. (1967). Gastrointestinal actions of metoclopramide: an experimental study. Gastroenterology, 52 , 676-684.

James, W. B., and Hume, R. (1968). Action of metoclopramide on gastric emptying and small bowel transit time. Gut, 9, 203-205.

Johnson, H. D. (1957). The pathogenesis of peptic ulcers. Lancet, 2, 515-517.

Justin-Besancon, L., and Laville, C. (1964). Action antiémétique du métoclopramide vis-à-vis de l'apomorphine et de l'hydergine. C.R. Soc. Biol. (Paris), 158, 723-727.

,-- , and Thominet, M. (1964). Le métoclopramide et ses homologues introduction à leur étude biologique. C.R. Acad. Sci. (Paris), 258, 4384-4386.

Margieson, G. R., Sorby, W. A., and Williams, H. B. L. (1966). The action of 'metoclopramide' on gastric emptying: a radiological assessment. Med. J. Aust., 2, 1272-1274. 